\title{
Pela democracia dos sistemas de avaliação da produção acadêmica: convergências de estudiosos latino-americanos e europeus*
}

\author{
AIMÉE VEGA MONTIEL \\ Universidade Autônoma do México \\ Tradução de Ana Paula C. Renesto \\ Revisão técnica de Rosália Maria Duarte
}

\section{NOTA INTRODUTÓRIA}

A contribuição de estudiosos latino-americanos para os estudos de mídia e comunicação tem sido muito significativa. No entanto, o diálogo e o intercâmbio com estudiosos do Norte geralmente não se dão em termos de igualdade, mas de hierarquia. Por quê? Os estudiosos que integram as comunidades do Sul não participam ativamente da definição dos modelos e sistemas projetados para medir e avaliar a produção acadêmica. Embora haja metodologias e instrumentos específicos sendo utilizados em contextos locais e regionais, a produção acadêmica dos estudiosos do Sul normalmente é submetida às regras definidas em outras latitudes do mundo - em latitudes onde existem problemas sociais distintos e diferentes condições científicas para a pesquisa.

* O presente texto é transcrição de conferência proferida, em 2011, no encontro anual da European Communication Research and Education Association (ECREA). 
Os efeitos disso são evidentes em pelo menos dois cenários: o primeiro é o da construção do objeto de estudo; e o segundo é o da influência sobre a agenda de pesquisa.

Nessa lógica - a lógica do mercado -, que tende a legitimar algumas poucas teorias, métodos e problemas, a competitividade impõe-se sobre a cooperação, o que tende a ser a regra de nossa produção e organização (Ortiz, 2004).

Portanto, este texto é motivado por um desejo de colocar em pauta alguns dos efeitos desse processo nas comunidades científicas que, como veremos, são condicionadas por sua relação com o idioma inglês.

\section{OS PROBLEMAS ESTRUTURAIS}

Temos de admitir que há uma estrutura desigual de produção e disseminação de conhecimento no sistema científico internacional. Isso é o efeito de vários processos, tanto externos quanto internos ao nosso campo.

Os processos externos têm relação com dois aspectos principais. $O$ primeiro deles é o domínio do capitalismo neoliberal dos critérios de qualificação do conhecimento científico (Fuentes, 1997). O segundo aspecto é a posição dominante ocupada pelas ciências naturais na definição de regras para avaliar a produção acadêmica em todas as áreas, incluindo as ciências sociais. A ideia de um pesquisador em seu laboratório, publicando um artigo e sendo multicitado tornou-se um padrão universal para definir "qualidade" no trabalho acadêmico. Esse sistema corrói o valor e as possibilidades de outras formas de disseminação do conhecimento, incluindo livros.

Os processos internos estão relacionados com o predomínio das potências das ciências sociais (EUA e Europa) sobre as comunidades do Sul, como a América Latina. A socióloga argentina Fernanda Beigel (2010) chama esse fenômeno de "dependência acadêmica".

Eis algumas das expressões desse domínio:

1) O sistema de publicação. Esse sistema estabeleceu normas de publicação universais que definem a qualidade do que é bom no mundo anglo-saxão. O sistema vai além e estabelece regras básicas para um trabalho qualificado. O inglês é a única língua válida para publicar, de acordo com ele. Para os pesquisadores não anglo-saxões, essa exigência afeta sua identidade e seus processos de criação, o que, na perspectiva de Divina Frau-Meigs (2012, p. 76), "transforma-nos em empresários da pesquisa (publicar ou perecer), em vez de criadores e inovadores". Um efeito central disso é que o conhecimento produzido em outros idiomas que não o inglês tem um impacto reduzido e uma má circulação internacional, bem como um lugar inferior no sistema hierárquico acadêmico (Beigel, 2010). Um exemplo é o Social Science Citation Index (Índice de Citações em Ciências Sociais), uma base de dados limitada não apenas porque se restringe à produção científica em inglês, mas também pelos critérios de construção do instrumento, que, de 
acordo com Fernanda Beigel, coloca principalmente publicações dos EUA como revistas de "alto impacto".

2) Associada a esse efeito está a manipulação do reconhecimento científico por editoras, geralmente localizadas nas regiões Norte (Beigel, 2010).

3) Outra implicação do domínio é a mudança nas avaliações institucionais, hoje influenciadas principalmente por entidades externas às universidades. De acordo com Beigel (idem), nos anos 1960, órgãos públicos e fundações privadas - como as Fundações Ford e Rockefeller, a Organização dos Estados Americanos (OEA), a Organização para a Cooperação e Desenvolvimento Econômico (OCDE) - começaram a competir pela influência cultural e ideológica na América Latina e outras regiões do Sul com vistas ao progresso econômico. $\mathrm{O}$ que os estados latino-americanos fizeram foi permitir que essas organizações definissem os critérios para avaliar a produção acadêmica.

4) Uma quarta expressão do domínio é a influência de entidades globais, como a Organização das Nações Unidas para a Educação, a Ciência e a Cultura (UNESCO), sobre a definição das agendas de pesquisa. Isso afeta diretamente os objetos de estudo, teorias e métodos e, em consequência, o financiamento que universidades, organizações e governos concedem à pesquisa. O inconveniente disso é que há muitos problemas nas regiões do Sul que, por não se qualificarem como uma prioridade, tornam-se invisíveis. Portanto, pode ser difícil encontrar uma solução para eles.

Apesar dessas condições, os estudiosos latino-americanos construíram uma identidade própria forte, evidente nas perspectivas de Jesús-Martin Barbero, Rosa María Alfaro, Rossana Reguillo, Antonio Pasquali e Néstor García Canclini. Mas o problema é que, como suas obras são principalmente publicadas em espanhol, elas permanecem invisíveis.

Assim, o problema central é a supremacia do inglês no sistema acadêmico internacional, o qual limita as possibilidades de disseminação do conhecimento em outras línguas.

\section{O PROBLEMA DO INGLÊS}

O antropólogo brasileiro Renato Ortiz escreve em As ciências sociais e o inglês $(2004$, p. 5) que a "globalização declina-se preferencialmente em inglês". No reino da ciência, isso é paradoxal, já que por um lado o valor e a finalidade prática do inglês para o nosso trabalho é muito importante. É a língua que permite a nós, não anglo-saxões, estabelecer comunicação não apenas com pesquisadores ingleses e americanos, mas também com outros europeus (portugueses, franceses) ou pesquisadores asiáticos e assim por diante, para chegar a acordos para melhorar a qualidade de vida das sociedades. Por outro lado, o predomínio linguístico do inglês não contribui para o sentido coletivo do nosso trabalho. Em vez disso, divide-o 
ao estabelecer uma hierarquia. Tais efeitos são expressos em níveis de esboço de pensamento e de ação, que podem ser resumidos em uma grande implicação: a influência das comunidades científicas anglo-saxãs sobre a construção do objeto de estudo, ou seja, sobre as definições teóricas e metodológicas utilizadas para a pesquisa. Quando traduzimos para o inglês, nas palavras de Divina Frau-Meigs, a essência de uma noção se perde; a tradução pode perder conceitos. Segundo ela,

O exemplo de conceitos se relaciona diretamente com a identidade e, por meio dela, com os direitos individuais da pessoa, especialmente à dignidade. Tal é o caso do estilo, o que é ainda mais irritante que o das ideias. A maioria dos pesquisadores passam a vida inteira aperfeiçoando suas frases, esculpindo um parágrafo por horas e dias a fio, acrescentando uma nuance que parece correta. Os mais famosos entre nós tendem a ser os que têm o equilíbrio perfeito entre ideias e estilo. E tudo pode desaparecer na tradução, já que os tradutores tendem a dissipar a ambiguidade e esclarecer noções para que os leitores não achem que há problemas na tradução. (Frau-Meigs, 2012, p. 76)

Pelo que foi explicado aqui, sabemos que tanto publicar quanto ser citado em inglês são altamente valorizados, e às vezes isso é prejudicial para as ideias. Lembro-me da confissão triste que um investigador europeu fez na conferência do European Communication Research and Education Association (ECREA), realizada em Barcelona em novembro de 2008: ele salientou que o seu interesse em trabalhar com universidades e pesquisadores latino-americanos tinha sido prejudicial para a sua produtividade, pois as publicações em espanhol não são reconhecidas nas avaliações do seu país.

Assim, a utilidade do inglês no contexto da globalização é um fato indiscutível. É uma ferramenta de comunicação útil, mas sua prevalência também criou uma hierarquia de idiomas e, nas palavras de Renato Ortiz (2004), a consequente segregação intelectual gera desigualdades entre nós.

Historicamente, temos vivido o risco, a ameaça constante do estabelecimento de um modelo hegemônico que representa o mundo que legitima teorias, métodos e problemas. O modelo é amplamente conhecido: o mercado. Nesse contexto, os cientistas não fogem a seu domínio, que é o que governa a sociedade e a nós como parte dela. Ele governa nossa lógica de produção e participação. Assim, as exigências de concorrência que prevalecem sobre as de cooperação invadiram o campo científico e existe, portanto, uma ameaça latente de que a ação científica coletiva seja minada (Vega, 2009).

Compreendo que todos os pesquisadores do mundo estão submetidos a esses sistemas. Então eu pergunto: O que nós, como comunidade, podemos fazer?

Como penso que esse é um problema intimamente relacionado com os direitos humanos, temos de concentrar nossa atenção no desenvolvimento de formas criativas de cooperação. Estas são minhas propostas: 
1. Promoção contínua da representação de todas as regiões em órgãos de consultoria do International Association for Media and Communication Research (IAMCR), em organizações como a UNESCO - para influenciar a agenda de pesquisa - e editoras - para encorajá-las a publicar trabalhos com qualidade comprovada em outros idiomas além do inglês.

2. Sugiro amplamente que a IAMCR seja o meio pelo qual os pesquisadores de comunicação do mundo todo influenciem as políticas de produção científica. Nesse ponto, penso que nós precisamos de uma representação em entidades globais, como a OCDE, para influenciar os critérios de avaliação acadêmica.

3. Apoio às atividades que dão destaque à pesquisa de comunicação regional, em coordenação com as associações regionais. Nesse ponto, proponho que a Asociación Latinoamericana de Investigadores de la Comunicación (ALAIC) e a ECREA liderem a construção de redes de pesquisa para estimular a produção coletiva de conhecimento com visibilidade no sistema científico internacional.

4. Estímulo à pesquisa e publicação de análises regionais, buscando a participação de editoras regionais.

5. Outra proposta tem relação com o uso de Open Access, bem como de outras bases de dados alternativas.

Quero encerrar minha palestra citando Renato Ortiz (2004, p. 18):

[...] se pensarmos em termos do contexto, deveríamos dizer que o ideal seria o conhecimento de todas as línguas nas quais as ciências sociais se exprimem, para se obter, não uma universalização do espírito, mas uma biblioteca de idiomas a serviço de uma maior riqueza do pensamento. Embora isso seja irrealizável, é importante tê-lo em mente, pois o cosmopolitismo das ideias somente pode existir quando levamos em consideração a diversidade dos contextos e os "sotaques" das tradições sociológicas.

Salud.

\section{REFERÊNCIAS}

Beigel, Fernanda. Presentation: the challenge of constructing autonomous social sciences in the South. In:Workshop on Academic Dependence, II., 2010, Mendoza, Argentina. Disponível em: <http://www.clacso.org.ar/>. Acesso em: dez. 2012.

Frau-Meigs, Divina. Languages, research and human rights. In: Vega Montiel, Aimée (Ed.). Communication and human rights. México: UNAM/IAMCR, 2012. p. 73-79.

Fuentes, Raúl. Academic communication research in Mexico, notes for a reflexive balance sheet. Mexican Journal of Communication, México: Fundación Manuel Buendía, n. 3, p. 59-77, jul. 1997. 
Ortiz, Renato. As ciências sociais e o inglês. Revista Brasileira de Ciências Sociais, São Paulo: ANPOCS, v. 19, n. 54, p. 5-22, fev. 2004.

Vega, Aimée. Towards linguistic diversity in IAMCR. In: Vega Montiel, Aimée (Ed.). Communication and human rights. México: UNAM/IAMCR, 2009. p. 69-72.

\section{SOBRE A AUTORA}

Aimée Vega Montiel é doutora em jornalismo e ciências da comunicação pela Universidade Autônoma de Barcelona. Professora da Universidade Autônoma do México (UNAM).

E-mail: aimeevegamx@yahoo.com.mx

Recebido em dezembro de 2012

Aprovado em dezembro de 2012 


\section{AIMÉE VEGA MONTIEL}

\section{Pela democracia dos sistemas de avaliação da produção acadêmica: convergências de estudiosos latino-americanos e europeus}

O presente texto é transcrição de conferência proferida, em 2011, no encontro anual da Europeean Comunication Research and Education Association (ECREA), que coloca em pauta os efeitos da supremacia dos pesquisadores do Norte sobre os pesquisadores do Sul no contexto da avaliação da qualidade da produção acadêmica. Embora sejam reconhecidas as especificidades locais e regionais, assim como a necessidade de adoção de diferentes metodologias e instrumentos de pesquisa para o estudo de problemas distintos, em contextos sociais diversos, a produção acadêmica dos estudiosos latino-americanos segue sendo submetida a padrões definidos em outras latitudes do mundo. Argumenta-se que a supremacia científica dos pesquisadores do Norte deve-se, fundamentalmente, à supremacia do inglês no sistema acadêmico internacional, a qual limita as possibilidades de disseminação do conhecimento em outras línguas.

Palavras-chave: supremacia do idioma inglês; desigualdade; avaliação; produção científica. 


\section{For the democracy of the systems of evaluation of academic production: convergences of Latin American and European scholars}

This text is a transcript of a lecture given in 2011, at the annual meeting of the European Communication Research and Education Association (ECREA). Such lecture discusses the effects of the supremacy of the researchers from the North over the researchers from the South in the assessment of the quality of academic production. Local and regional specificities are recognized, as well as the need to adopt different methodologies and research tools for the study of different problems in different social contexts. However, the academic production of Latin American scholars remains subjected to standards set in other latitudes of the world. It is argued that the fundamental reason for the scientific supremacy of researchers from the North is the supremacy of the English language in the international academic system, which limits the possibilities of knowledge dissemination in other languages.

Keywords: supremacy of the English language; inequality; assessment; scientific production.

\section{Por la democracia de los sistemas de evaluación de la producción académica: convergencia de investigadores latinoamericanos y europeos}

El presente texto es la transcripción de una conferencia pronunciada en 2011, en el encuentro anual de la Europeean Comunication Research and Education Association (ECREA), que plantea la discusión sobre los efectos de la supremacia de los investigadores del norte sobre los investigadores del sur en el contexto de la evaluación de la calidad de la producción académica. Aunque se reconozcan las especificidades locales y regionales, así como la necesidad de adopción de diferentes metodologías e instrumentos de investigación para el estudio de problemas distintos, en contextos sociales distintos, la producción académica de los estudiosos latinoamericanos sigue siendo sometida a patrones definidos en otras latitudes del mundo. Se argumenta que la supremacía cientifica de los investigadores del norte se debe, fundamentalmente, a la supremacía del inglés en el sistema académico internacional, que limita las posibilidades de diseminación del conocimiento en otras lenguas.

Palabras clave: supremacía del idioma inglés; desigualdad; evaluación; producción cientifica. 